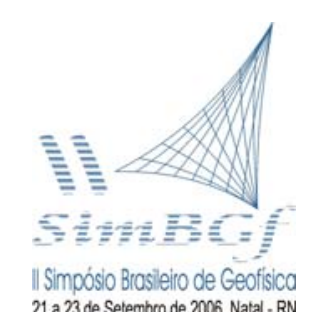

,21 a 23 de Setembro de 2006, Natal - RN

\title{
CARACTERIZAÇÃO FÍSICA DE ESTUÁRIOS HIPERSALINOS DO LITORAL SETENTRIONAL DO ESTADO DO RIO GRANDE DO NORTE, BRASIL
}

\author{
M. P. da Silva, UFRN; L. B. Miranda, USP; C. A. Ramos e Silva, UFRN; E. P. Frazão, UFRN e F. E. S. de Souza
}

Copyright 2006, SBGf - Sociedade Brasileira de Geofísica

Este texto foi preparado para a apresentação no II Simpósio de Geofísica da Sociedade Brasileira de Geofísica, Natal, 21-23 de setembro de 2006. Seu conteúdo foi revisado pela Comissão Tecno-científica do II SR-SBGf mas não necessariamente representa a opinião da SBGf ou de seus associados. E proibida a reprodução total ou parcial deste material para propósitos comerciais sem prévia autorização da SBGf.

\section{Resumo}

Neste trabalho são reportadas as primeiras observações de parâmetros hidrográficos e de correntes nos estuários Apodi-Mossoró, Piranhas-Açu, Guamaré e Galinhos. Localizados no litoral setentrional do RN, Brasil, ultimamente eles têm sofrido impactos ambientais ligados às atividades sócio-econômicas da região. Os estuários observados apresentaram altos valores de salinidade $(40<S<52)$, perfil de temperatura com pequena estratificação vertical (médias entorno de $28^{\circ} \mathrm{C}$ ) e baixa estratificação nos perfis das correntes $(<0,30 \mathrm{~m} / \mathrm{s}$ ), próximo à estofa de vazante. Considerando as baixas vazões dos rios, as taxas de evapotranspiração da região e seus perfis hidrográficos e de corrente, esses estuários possuem características "hipersalinas", são forçados predominantemente pela maré, podendo ser classificados como "Verticalmente Bem Misturado".

\section{Introdução}

Ultimamente, os estuários do litoral setentrional do Estado do Rio Grande do Norte, Brasil, vêm sofrendo sérios impactos ambientais devido às atividades humanas, com destaque às salineiras, de carcinocultura, de exploração petrolífera e ao despejo de efluentes sanitários urbanos.

Por outro lado, o entendimento das características físicas desses estuários, representa, juntamente com outras variáveis ambientais, uma importante contribuição para a implantação de um programa de monitoramento da qualidade da água, para o zoneamento ecológicoeconômico do litoral do RN e para a sustentabilidade desses ambientes naturais.

Os principais objetivos do trabalho são: (a) descrever a variação espacial das características termohalinas e da corrente dos estuários nas piores condições antropogênicas. Tal especificidade levou a realização das observações no período de menor precipitação, em maré de quadratura e próximo à estofa de vazante; (b) classificar os estuários com base nas suas características termohalinas e de corrente.

Esse trabalho foi realizado como parte da investigação dos efeitos de fontes antropogênicas (salineira, carcinicultura e dejetos orgânicos) na qualidade da água dos estuários do litoral norte do $\mathrm{RN}$, financiado pelo Instituto de Desenvolvimento Econômico e Meio Ambiente do Estado do Rio Grande (IDEMA), sendo estes os primeiros relatos na literatura científica dos estudos do gênero aplicados àqueles corpos d'água.

\section{Metodologia/ Problema Investigado}

A aquisição dos parâmetros físicos foi feita em maré de quadratura, sendo as medidas realizadas na transição entre o meio ciclo de vazante para enchente, obedecendo-se um intervalo de amostragem de aproximadamente 02 horas, entre o início e o fim dos experimentos.

Para as medidas dos parâmetros hidrográficos e de corrente foi utilizado um sistema CTD/Correntômetro VALEPORT, modelo 108MkIII/308, equipado com sensores eletrônicos do tipo CTD (Conductivity, Temperature and Depth/Pressure).

Como plataforma de trabalho, utilizou-se uma embarcação de baixo calado $(<1,0 \mathrm{~m})$ como plataforma de trabalho, fato que permitiu a navegabilidade em áreas de pequena profundidade. Os perfilamentos foram feitos desde a superfície até as proximidades do fundo, separados por intervalos de profundidade de 0,5 m.

As propriedades hidrográficas de cada estuário foram medidas em estações ao longo dos seus respectivos canais principais de navegação, posicionadas com base nos seus aspectos morfológicos e de batimetria (Vital et al., 2003).

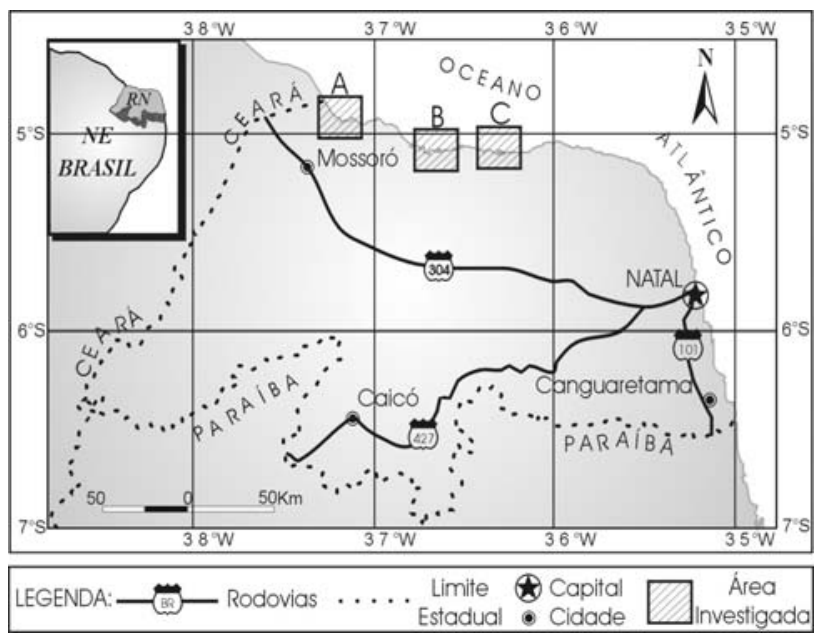

Figura 1 - Litoral do RN. A, B e C são localizações dos estuários investigados 
Figura 3 - Distribuição de Salinidade do Piranhas-Açu

\section{Resultados}

Tomando por base as variações horárias dos níveis de maré para o município de Macau/RN, conforme dados da Diretoria de Hidrografia e Navegação (DHN) do Ministério da Marinha, a análise das constantes harmônicas de maré, calculadas de acordo com Franco(2000), apresentou as amplitudes, em $\mathrm{cm}$, de $\mathrm{O}_{1}=6,58, \mathrm{~K}_{1}=7,46$, $\mathrm{M}_{2}=91,38$ e $\mathrm{S}_{2}=30,30$.

Pode-se, portanto, inferir o tipo de maré na região a partir da definição do Número de Forma $N_{f}$, expresso pela equação 1 (Miranda et al., 2002)

$N_{f}=\frac{K_{1}+O_{1}}{M_{2}+S_{2}}$

Como conseqüência, $N_{f}=0.11$, implicando no fato de que a maré na região é do tipo semidiurna.

As figuras 2,3,4 e 5 mostram as distribuições de salinidade para os diversos estuários observados.

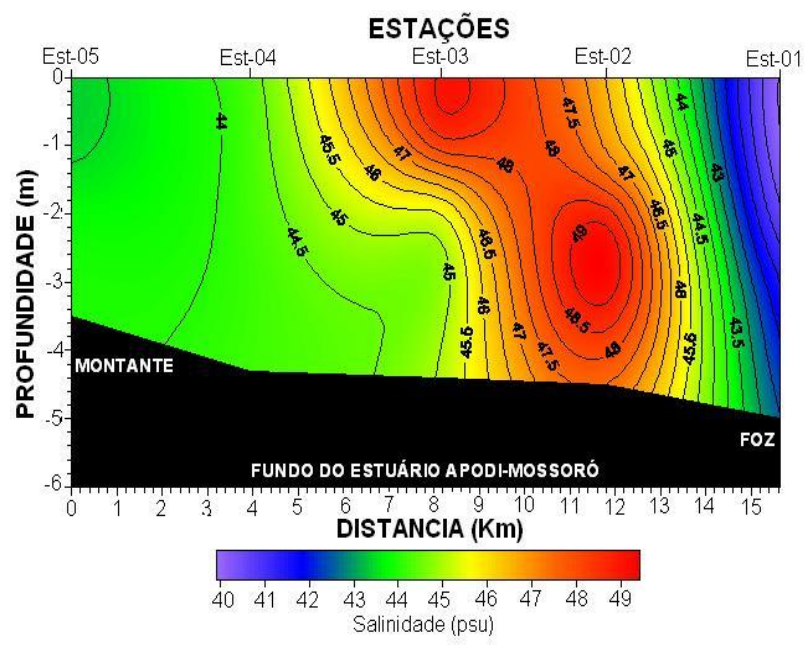

Figura 2 - Distribuição de Salinidade do Apodi-Mossoró

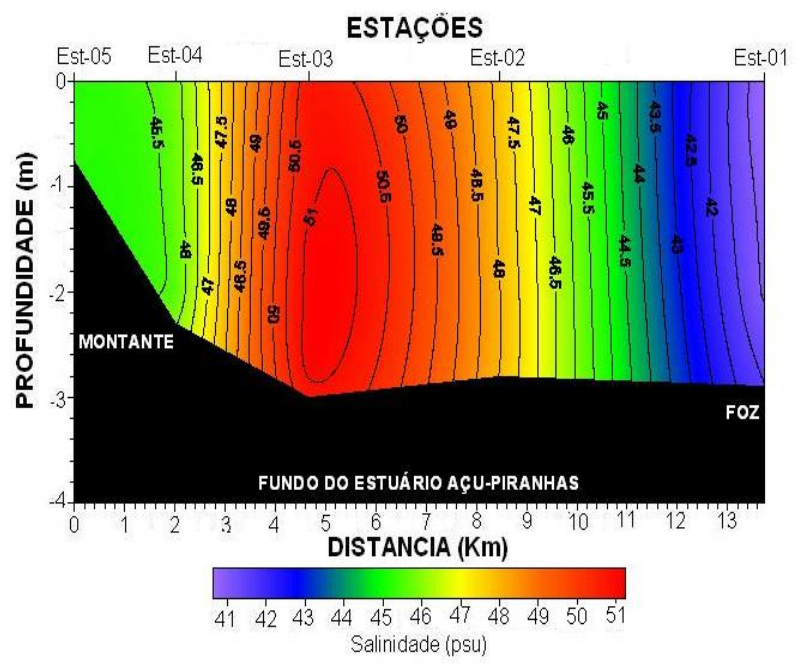

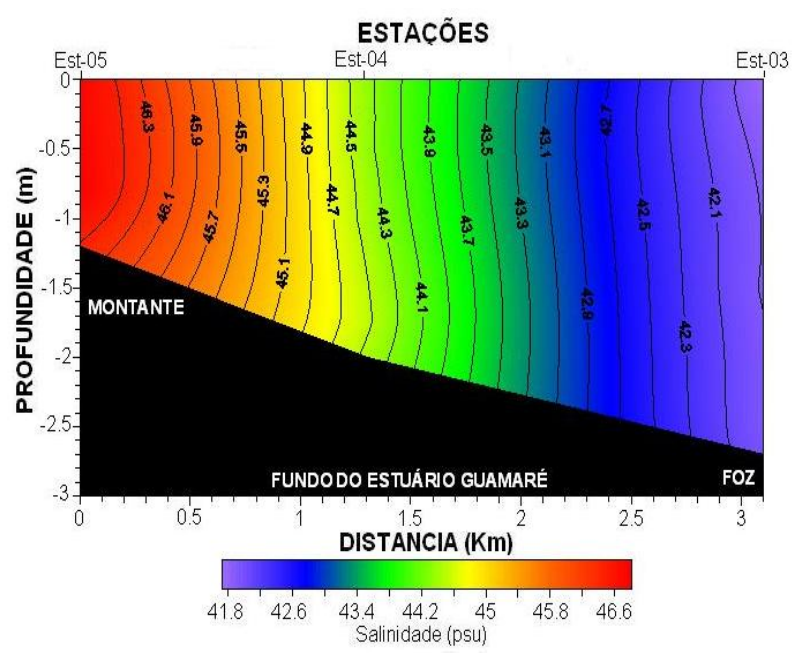

Figura 4 - Distribuição de Salinidade do Guamaré

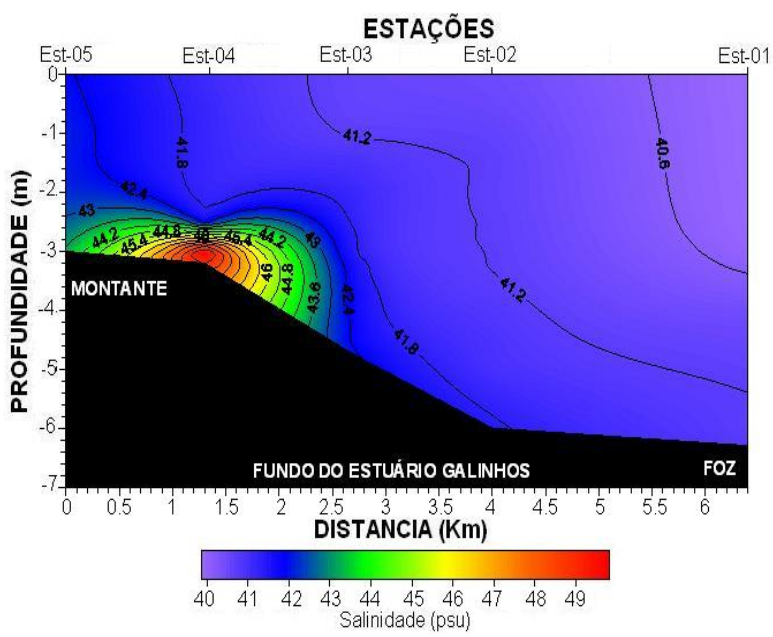

Figura 5 - Distribuição de Salinidade de Galinhos

As figuras 6, 7, 8 e 9 exibem, respectivamente, as distribuições de temperatura para os estuários de Apodi/Mossoró, Piranhas/Açu, Guamaré e Galinhos. 


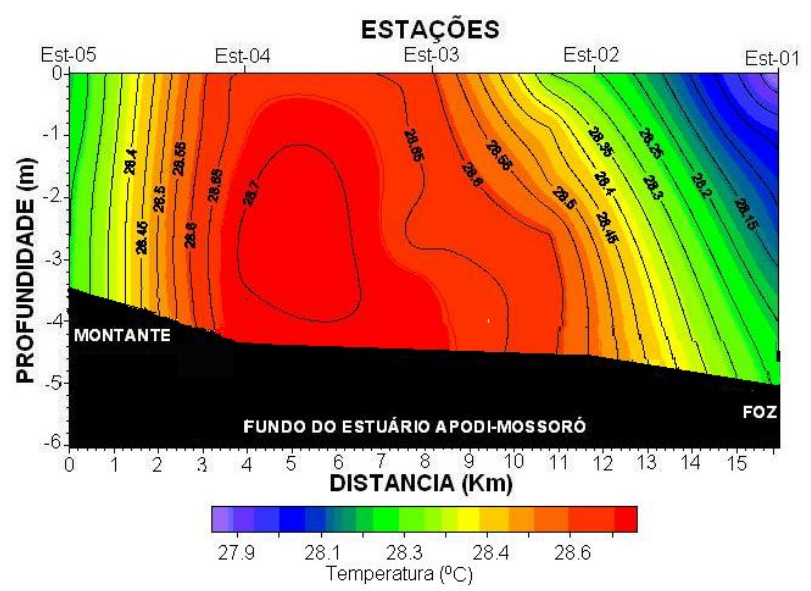

Figura 6 - Distribuição de Temperatura de Apodi-Mossoró

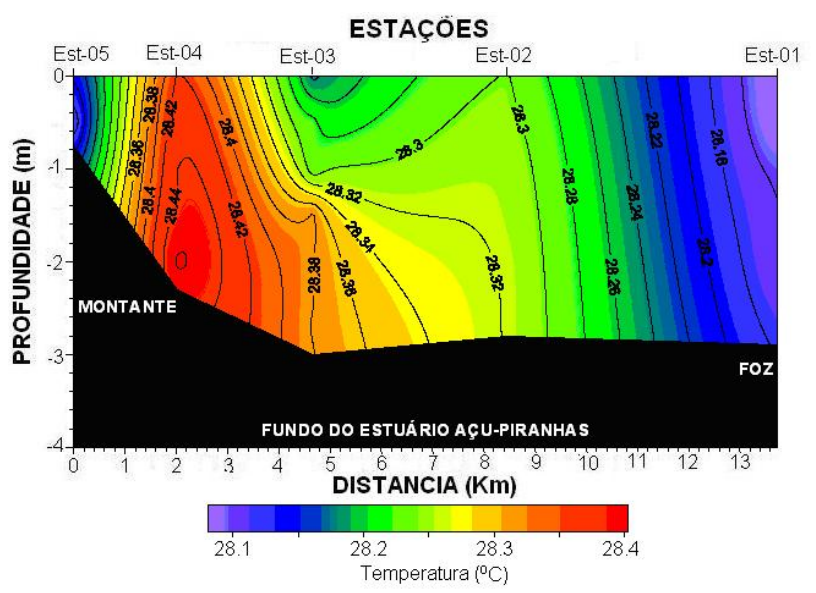

Figura 7 - Distribuição de Temperatura do estuário Piranhas-Açu

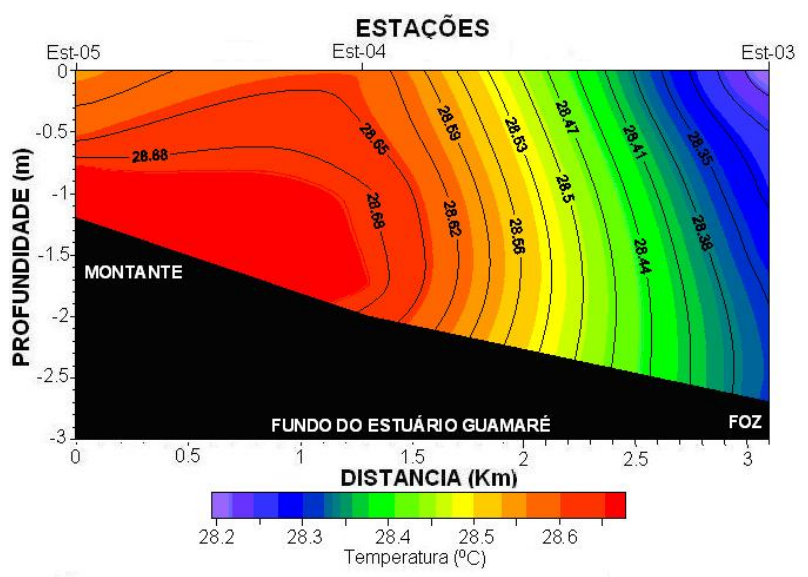

Figura 8 - Distribuição de Temperatura do estuário Guamaré

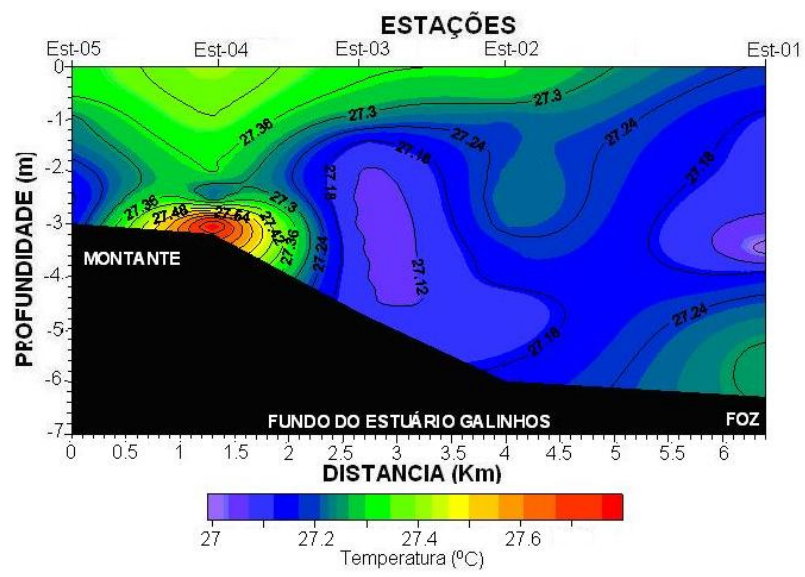

Figura 9 - Distribuição de Temperatura do estuário de Galinhos

Devido à necessidade de se criar um mapa de correntes de cada estuário, os vetores de corrente foram decompostos nas respectivas direções $\boldsymbol{u}$ e $\boldsymbol{v}$, longitudinal e transversal ao estuário, orientadas segundo um ângulo $\gamma$ em relação ao norte verdadeiro. Assim, o argumento $\theta$ para a decomposição do vetor velocidade é dado por:

$$
\theta=90^{\circ}-(d d-D)+\gamma
$$

onde, $\boldsymbol{d} \boldsymbol{d}$ é a direção da velocidade com relação ao norte verdadeiro e $\boldsymbol{D}$ é a declinação magnética, $\left(22^{\circ} 15^{\prime} \mathrm{W}\right.$ em nov/2003), de acordo com os dados obtidos de cartas náuticas da região.

As figuras 10,11, 12 e 13 mostram as variabilidades dos perfis verticais da componentes longitudinais da corrente u, tomadas ao longo de cada estuário, sobre cada uma das estações de coleta de dados e calculadas a partir da equação 2. Valores positivos e negativos indicam movimentos de vazante (estuário abaixo) e de enchente (estuário acima), respectivamente. As linhas em cores indicam as correntes medidas nas várias estações de observação.

Para efeito de cálculo das correntes, usou-se a condição de atrito máximo no fundo (a componente vertical da corrente é zero).

No tocante à salinidade, verifica-se que todos os estuários pesquisados apresentam altas concentrações de sal, exibindo valores que variam entre $S \approx 40,0$ a $\mathrm{S} \approx 51,0$. Por outro lado, as temperaturas variam entre $\mathrm{T} \approx 27,0^{\circ} \mathrm{C}$ e $\mathrm{T} \approx 28,6^{\circ} \mathrm{C}$. Entretanto, as respectivas distribuições espaciais dessas propriedades variam ligeiramente entre os diversos estuários. A tabela 1 apresenta os valores máximos e mínimos de salinidade e temperatura para os vários estuários estudados. 

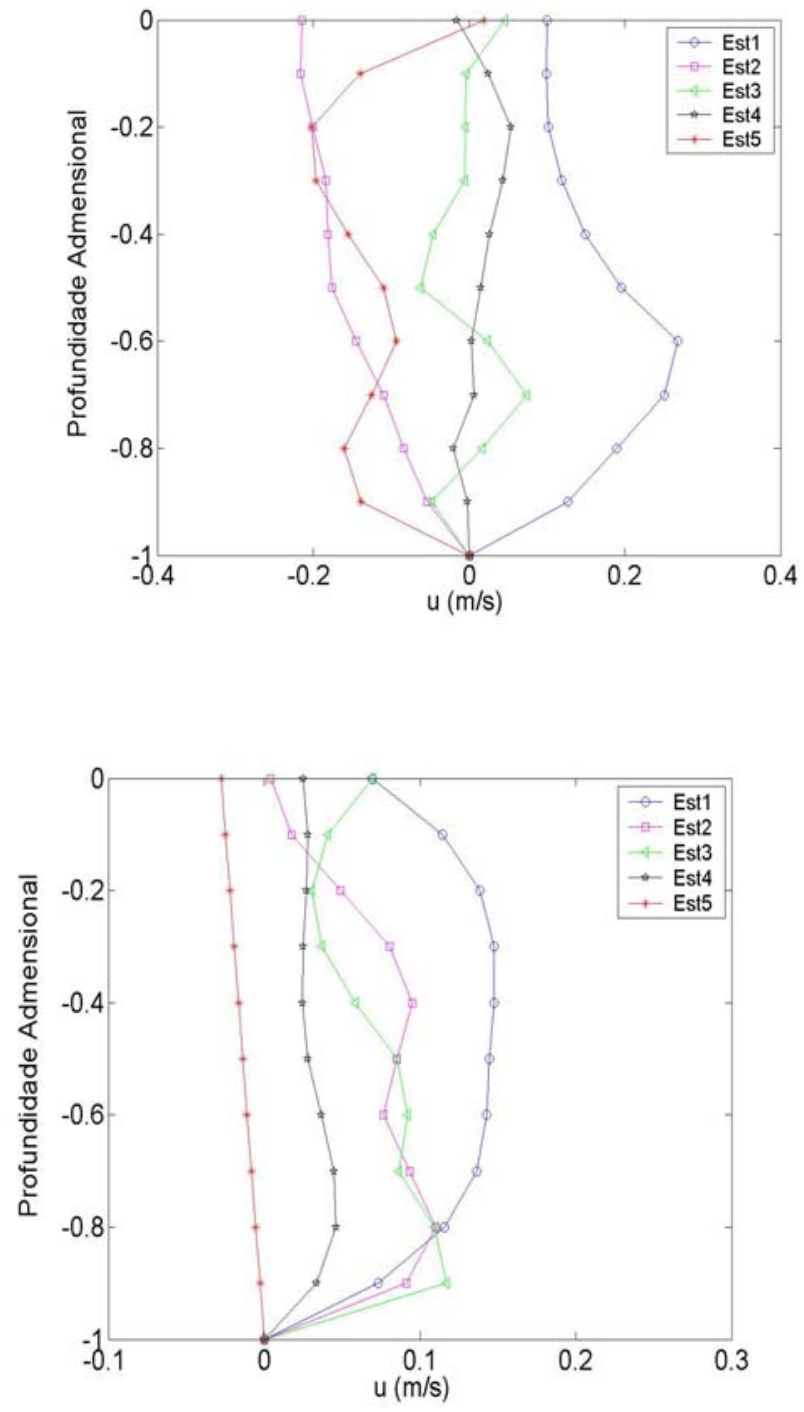

Figura 10 - Perfil da componente longitudinal u da corrente no estuário Apodi-Mossoró

Figura 11 - Perfil da componente longitudinal u da corrente no estuário Piranhas-Açu

Por outro lado, verifica-se na estrutura longitudinal de salinidade do estuário Apodi-Mossoró, que esta aumenta estuário acima passando por um valor máximo próximo a $\mathrm{S}=49,0$, entre as estações 02 e 03 (em núcleos superficial e próximo ao fundo).

Próximo à zona do rio observa-se uma fraca influência da diluição da descarga do rio Mossoró. Os valores mais elevados de salinidade encontrados entre as estações 02 e 03 são, provavelmente, reflexos da contaminação

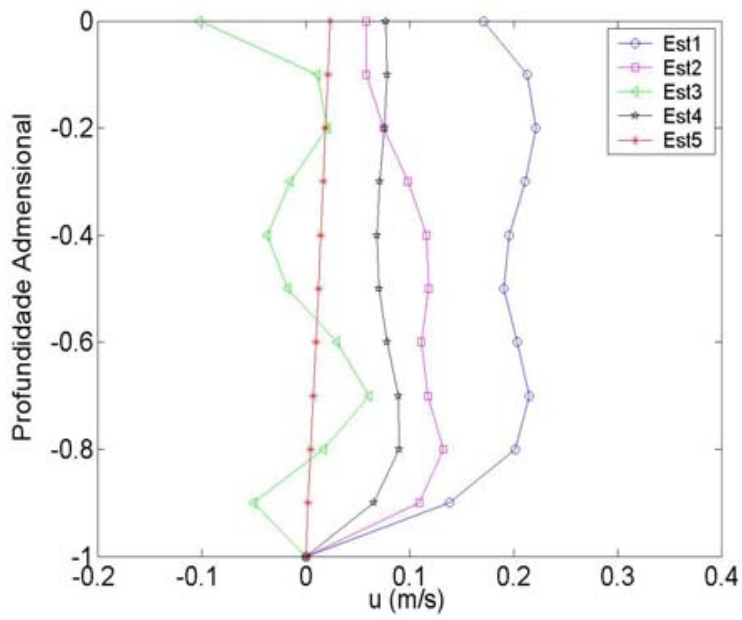

Figura 12 - Perfil da componente longitudinal u da

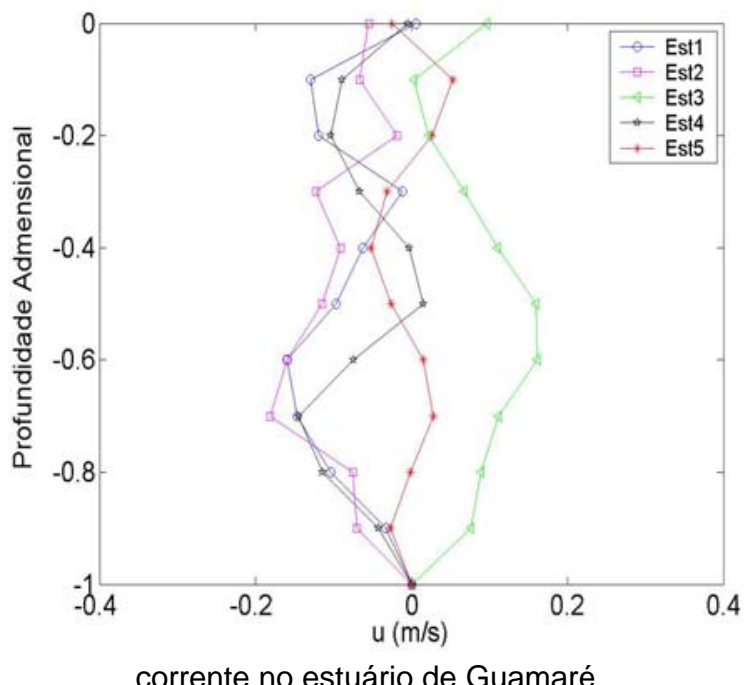

Figura 13 - Perfil da componente longitudinal $u$ da corrente no estuário de Galinhos

Tabela 1 - Valores máximos e mínimos de salinidade e temperatura dos vários estuários observados

\begin{tabular}{|ccccc|}
\hline Estuário & $\mathrm{S}_{\operatorname{máx}}$ & $\mathrm{S}_{\min }$ & $\mathrm{T}_{\operatorname{máx}}$ & $\mathrm{T}_{\min }$ \\
\hline Apodi-Mossoró & 49,0 & 40,0 & 28,6 & 27,9 \\
Açu-Piranhas & 51,0 & 40,0 & 28,4 & 28,1 \\
Guamaré & 46,6 & 41,8 & 28,7 & 28,3 \\
\hline
\end{tabular}




\begin{tabular}{|lllll|}
\hline Galinhos & 49,6 & 40,6 & 28,0 & 27,0 \\
& & & & \\
\hline
\end{tabular}

devido à atividade salineira que é proeminente na região investigada. O estuário de Galinhos, por sua vez, apresenta núcleos isolados de alta salinidade ao longo do estuário, fruto, possivelmente, do mesmo tipo de atividade na região. As características gerais dos campos de salinidade de todos os estuários pesquisados indicam tratar-se de estuários hipersalinos e com fraca estratificação vertical.

\section{Discussão e Conclusões}

Nota-se em todos os estuários investigados, que os valores da salinidade são elevados na direção estuário acima, com maior concentrando em determinados pontos do mesmo. Este fato possivelmente está condicionado à efluentes decorrentes da atividade salineira na região.

Por outro lado, levando-se em consideração que as medidas de corrente foram feitas em instantes próximos à estofa de vazante, suas intensidade são relativamente fracas, atingindo o valor máximo de 0,27 m/s Estação 1 do estuário Apodi-Mossoró. Por outro lado, com exceção da corrente na Estação 1 do estuário Apodi-Mossoró, os perfis verticais da componente longitudinal da corrente ao longo das estações de coleta de dados exibem valores aproximadamente uniformes ao longo da vertical, excetuando-se as camadas mais próximas ao fundo, onde $\mathrm{o}$ atrito reduz significativamente a intensidade das correntes. Este fato corrobora com o comportamento observado nas estruturas de salinidade e temperatura, dando a idéia de que os processos de mistura são forçados principalmente pela co-oscilação da maré e pelo efeito barotrópico da força de gradiente de pressão.

Das figuras 2 a 9, observa-se que, para todos os estuários, a distribuição longitudinal e vertical da salinidade quando associadas à quase-isotermia das massas de águas estuarinas, mostra conclusivamente que a densidade $\rho$ pode ser relacionada à salinidade $S$ através de uma equação linear de estado da forma: $\rho=\rho_{o}(1+\beta . S)$, onde $\beta$ denota o coeficiente de contração salina.

Embora não se tenha adotado qualquer tipo de modelagem na descrição dos perfis das correntes ao longo das estações, esse comportamento quase uniforme pode ser uma manifestação de densidade praticamente uniforme, uma vez que, por se tratar de áreas rasas, estratificações na corrente implicariam em possíveis interações entre as marés e os campos de temperatura e salinidade, ocasionando cizalhamentos significativos, com circulações em camadas diferentes da água.

Notadamente, esses sistemas hipersalinos, sendo corpos de água nos quais a massa de água do mar advectada para o seu interior pelas correntes de maré, têm a salinidade concentrada devido a influência desprezível da descarga fluvial e à maior taxa de evaporação em relação à precipitação.

Nesse sentido, a grande evaporação aumenta a salinidade e a densidade da superfície da água, provocando trocas com o fundo. O resultado líquido desse processo é o aumento da salinidade e, consequentemente, da densidade da água no fundo do estuário, de onde ela flui para o oceano. Sendo a água do oceano menos densa que a água que flui para fora do estuário, ela penetra no mesmo pela sua superfície, i.e., os fluxos e refluxos de água nesses ambientes costeiros são invertidos em relação à circulação de um estuário normal. Nesses casos, esses corpos d'água são também denominados "Estuários Inversos".

Além disso, se forem adotados para os mesmos os critérios clássicos de classificação dos estuários de acordo com a estratificação de salinidade de Pritchard (1955) e Cameron \& Pritchard (1963), os estuários do litoral setentrional do Estado do Rio Grande do Norte poderiam ser classificados como "Verticalmente Bem Misturados (ou Tipo C)".

Em resumo, as observações realizadas próximas às estofas de vazantes e em marés de quadratura se coadunam com o objetivo de descrever a variação espacial das características termohalinas e da corrente dos estuários nas piores condições antropogênicas.

Por outro lado, considerando as características das distribuições das propriedades termohalinas, a baixa extratificação vertical dos parâmetros e os respectivos perfis verticais da componente longitudinal das correntes pode-se concluir que, todos os estuários estudados são hipersalinos, forçado predominantemente pela maré., podendo serem classificados como "Verticalmente Bem Misturados".

\section{Agradecimentos}

Os autores agradecem ao Instituto de Desenvolvimento Econômico e Meio Ambiente do Estado do Rio Grande do Norte-IDEMA, pelo suporte financeiro parcial.

\section{Referências}

DHN - Diretoria de Hidrografia e Navegação da Marinha do Brasil. 2003. Cartas Batimétricas: Capitania dos Portos - NATAL/RN.

Franco, A. S., 2000. Marés: Programas para Previsão e Análise. In: Manual BSP, São Paulo. 36 p.

Vital, H. et al., 2004. Cartas batimétricas para os estuários Apodi-Mossoró, Piranhas-Açu, Guamaré e Galinhos. Natal: Rel. Parcial do Projeto ZEE do litoral do RN (IDEMA, Natal, RN). A ser publicado

Miranda, L. B.; Castro, B.M.; Kjerfve, B. Princípios de Oceanografia Física de Estuários. São Paulo: Editora da Universidade de São Paulo, 2002, 424 p. (Acadêmica 42).

Pritchard, D., 1955. Estuarine Circulation Patterns. Proc. Am. Soc. Civil Eng. 81:717:1-11. 
Cameron, W. M., Pritchard, D. W., 1963. Estuaries. In: Hill, M.N. (ed.) The Sea. Ideas and Observations on Progress in the Study of the Seas. New York. Intersci, pp. 306-324. 